\title{
THE SILENCE OF INNOCENCE
}

\author{
Ricardo Santos de Oliveira \\ ${ }^{1}$ Division of Neurosurgery \\ Ribeirão Preto Medical School, \\ University of São Paulo, São \\ Paulo, Brazil \\ To whom correspondence \\ should be addressed: Ricardo \\ Santos de Oliveira, MD, PhD \\ e-mail: rsoliveira30@gmail.com
}

Available at:

http://www.archpedneurosurg.com.br/

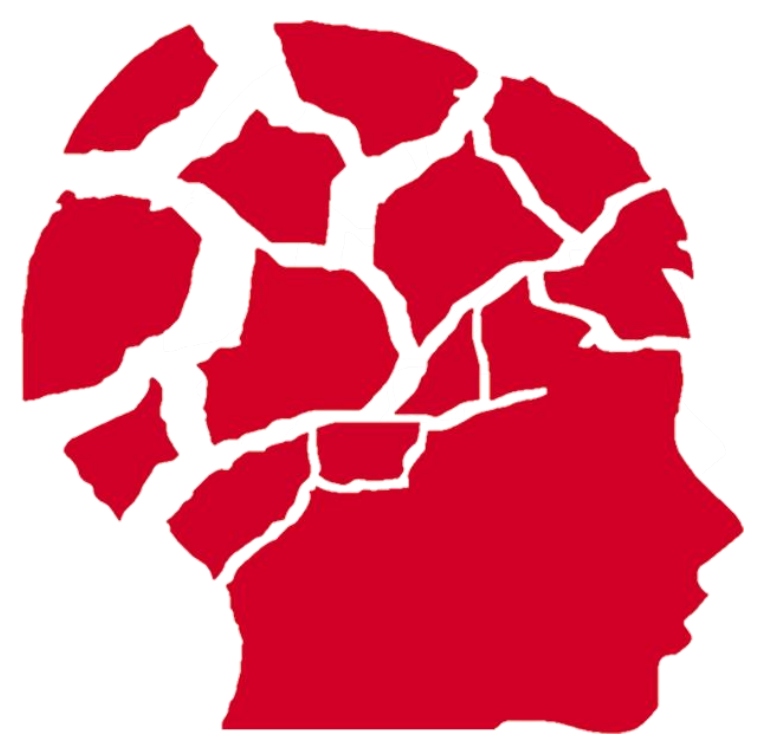

Keyworks: Neglect and abuse, fatal child abuse, non-fatal child abuse, prior abuse reports, perpetrator characteristics, substance use, risk and protective factors, ecological theory
The mysterious and suspicious death of the young Henry Borel on March 8, 2021 in Brazil brought up again the subject of child violence to the media. The child had multiple injuries in the abdominal cavity, pulmonary contusion, head trauma and other injuries incompatible with a domestic accident or fall in his room as reported by parents. Brazilian media has closely followed the case, offering continuous updates.

In Brazil, violence is a public health issue that hits population in a large scale, including children.

Violence against children takes many forms. It can be physical, emotional or sexual. It happens in all countries and any settings - in a child's home, community, school and online. In some parts of the world, violent discipline is socially accepted and common. And for many girls and boys, violence comes from the hands of the people they trust their parents or caregivers, teachers, peers and neighbours [1].

A perpetrator is a person who is responsible for the abuse or neglect of a child [3].

The National Child Abuse and Neglect Data System (NCANDS) showed that in 2019, about 252,324 children in the U.S. were abused by their mother [4]
Unfortunately, one or more parent is involved in $78 \%$ of child maltreatment fatalities.

Child maltreatment is a global problem with serious lifelong consequences. In spite of the recent national surveys in several low- and middle-income countries, data from many countries are still lacking [3].

Shaken Baby Syndrome / Abusive Head Trauma (SBS / $\mathrm{AHT}$ ) is a term used to describe the constellation of signs and symptoms resulting from violent shaking and impacting of the head of an infant or small child [5].

According to the WHO nearly 3 in 4 children - or 300 million children - aged 2-4 years regularly suffer physical punishment and/or psychological violence at the hands of parents and caregivers [3].

The Brazilian Society of Pediatrics (SBP) entered into a partnership with the Federal Council of Medicine (CFM) and the Ministry of Human Rights, to seek solutions against aggressions against children and adolescents.

On average, 233 assaults of different types (physical and psychological torture) against children and adolescents aged up to 19 years are notified in Brazil [6]. 


\section{THE SILENCE OF INNOCENCE}

In 2020, this pandemic has brought with it additional challenges in protecting young people from abuse and revealed gaps in our existing approach [7].

The stress in families and children will not end when the stay-at-home orders are lifted. Let's be prepared to help all our children emerge healthy and strong, and ready to learn.

Everyone knows violence is bad for children and adolescents, and sometimes fatal. It is harmful for them to be mistreated or abused by an adult, to be victimized by bullies, to witness serious domestic violence, or to be criminally assaulted. Many, though not all, young people who are exposed to violence react to this adverse experience by developing behavioral, emotional, or learning problems. What is less well known is that adverse experiences such as violence exposure can also lead to hidden physical alterations inside a child's body.

Some children exposed to violence learn to resolve their own conflicts in a violent manner. Others seem to become desensitized to violence and the pain and distress of others. Some retreat into a shell, avoiding people and the world around them. These children with long-term exposure are at an increased risk for:

- Behavioral, psychological, and physical problems

- $\quad$ Academic failure

- Alcohol and substance use

- Delinquent acts

- $\quad$ Adult criminality

Despite these grave physical and mental health consequences, the vast majority of child victims never seek or receive help to recover. What's more, children who grow up with violence are more likely to re-enact it as young adults and caregivers themselves, creating a new generation of victims.

Violence against children can be prevented. Preventing and responding to violence against children require that efforts systematically address risk and protective factors at all four interrelated levels of risk (individual, relationship, community, society). Do not underestimate child violence. Report it.

\section{REFERENCES}

1. Violence against children. https://www.unicef.org/protection/violence-againstchildren

2. Hornor, G. \& Zeno, R. (2018). Child Sexual Abuse Perpetrators: What Forensic Nurses Need to Know. J. Forensic Nurs. 14(4), 206-213.

3. Child maltreatment. https://www.who.int/newsroom/fact-sheets/detail/childmaltreatment

4. Preventing Child Abuse and Neglect: A Technical Package for Policy, Norm, and Programmatic Activities. https://www.cdc.gov/violenceprevention/pdf/CAN-

Prevention-Technical-Package.pdf

5. De Paula MCG, Pereira CU, Rabelo NN. Shaken Baby Syndrome: literature review in the last 5 years. Arch Pediat Neurosurg [Internet]. 2020Jul.16 [cited 2021Apr.12];2(2(May-August):e392020

6. https://veja.abril.com.br/brasil/brasil-registradiariamente-233-agressoes-a-criancas-e-adolescentes/

7. Agrawal

N. https://www.nytimes.com/2020/04/07/opinion/coronaviru s-child-abuse.html 